\title{
Desenvolvimento embrionário e eclodibilidade de ovos de codornas armazenados por diferentes períodos e incubados em umidades e temperaturas distintas
}

\author{
Adriana Ayres Pedroso ${ }^{1}$, Marcos Barcellos Café2, Nadja Susana Mogyca Leandro², José \\ Henrique Stringhini ${ }^{2}$, Leandro Silva Chaves ${ }^{2}$
}

\footnotetext{
${ }^{1}$ Bolsista de Desenvolvimento Científico Regional, Dep. de Produção Animal da Escola de Veterinária da Universidade Federal de Goiás, CEP: 74001-970, Goiânia/GO. Pesquisadora do CNPq.

2 Departamento de Produção Animal da Escola de Veterinária da Universidade Federal de Goiás, CEP: 74001-970, Goiânia/GO.
}

\begin{abstract}
RESUMO - Objetivou-se avaliar parâmetros relativos à incubação de ovos férteis de codornas japonesas. Os ovos foram armazenados por três períodos (0, 72 e 144 horas) e incubados em duas umidades relativas (55 e $65 \%)$ e duas temperaturas $\left(36,5\right.$ e $\left.37,5^{\circ} \mathrm{C}\right)$. Utilizou-se o delineamento inteiramente casualizado, em esquema fatorial $3 \times 2 \times 2$ (período de armazenamento $\mathrm{x}$ umidade $\mathrm{x}$ temperatura). As avaliações foram feitas às 276, 324, 362 e 420 horas de incubação e no momento da eclosão. Não houve interação significativa entre as variáveis estudadas. Inicialmente, a velocidade de desenvolvimento embrionário foi influenciada pelo período de armazenamento e pela temperatura da incubadora, mas, à medida que o processo incubatório avançou, o desenvolvimento embrionário se tornou similar entre os grupos experimentais. A mortalidade embrionária foi maior, especialmente na fase precoce, nos ovos armazenados por 144 horas e naqueles incubados a $65 \%$ de umidade relativa, após a bicagem da casca pela ave. O tempo necessário para a eclosão dos ovos foi menor quando incubados a $37,7^{\circ} \mathrm{C} \operatorname{com} 65 \%$ de umidade relativa e armazenados por períodos superiores a 72 horas. A eclodibilidade foi maior em ovos armazenados por até 72 horas. Ovos de codornas devem ser armazenados por períodos de até 72 horas e a incubação deve ser feita a $37,5^{\circ} \mathrm{C}$ e a 55 ou $65 \%$ de umidade relativa.
\end{abstract}

Palavras-chave: embrião, Coturnix coturnix japonica, incubação

\section{Embrionary development and hatchability of quail eggs stored for different periods and incubated at different humidity and temperatures levels}

\begin{abstract}
This study was carried out to evaluate the parameters related to hatchability of fertile eggs of Japanese quails. The eggs were stored for three periods ( 0,72 , and 144 hours), and incubated at two humidity (55 and 65\%) and two temperatures $\left(36.5\right.$ and $37.5^{\circ} \mathrm{C}$ ) levels. A complete randomized design with a 3 x 2 x 2 (storage period x humidity x temperature) factorial arrangement was used. Evaluations were performed at 276, 324, 362, and 420 hours of incubation and at hatch moment. There was no significant interaction among the studied variables. Initially, the speed of embryo development was affected by storage period and hatchery temperature, but as incubation period advanced the development was similar in all experimental groups. The embryo mortality, especially in the early phase, was higher in eggs stored for 144 hours and in eggs incubated at $65 \%$ of relative humidity, after shell breaking. The eclosion was faster in eggs incubated at $37.5^{\circ} \mathrm{C}, 65 \%$ of relative humidity and stored more than 72 hours. The hatchability was higher in the eggs stored until 72 hours. Quail eggs must be incubated at $37.5^{\circ} \mathrm{C}$ and 55 or $65 \%$ of relative humidity and stored until 72 hours.
\end{abstract}

Key Words: Coturnix coturnix japonica, embryo, incubation

\section{Introdução}

Métodos adotados na incubação de ovos de codornas costumam ser baseados em dados obtidos com pintos de corte. Em revisão, foi possível observar a escassez de estudos publicados envolvendo a incubação de ovos de codorna.

Segundo Fasenko (1996), é consenso que o estoque de ovos fertilizados diminui a sobrevivência embrionária proporcionalmente à duração da armazenagem. A eclodibilidade pode declinar quando o período de estocagem dos ovos excede três dias, independentemente da temperatura (Meijerhof et al., 1994). Além disso, tem-se observado que o ovo estocado pode apresentar maior período de incubação e retardamento do desenvolvimento embrionário (Reis et al., 1997).

O armazenamento dos ovos de codornas é realizado muitas vezes na granja, onde, em virtude do baixo nível 
tecnológico dos produtores, o processo é feito à temperatura ambiente. Além das perdas de água através dos poros da casca na fase pré-incubação (Sahan et al., 2003), o desenvolvimento embrionário de ovos mantidos acima do zero fisiológico ou $19^{\circ} \mathrm{C}$ (Decuypere \& Michels, 1992) pode se iniciar de forma inadequada.

A relação entre temperatura e umidade da incubadora foi extensivamente estudada e está padronizada para espécies como frangos, perus e patos (Cheng et al., 2005; Van Brecht et al., 2003; Applegate et al., 1999), entretanto, para outras espécies, como codornas, mais pesquisas devem ser desenvolvidas. Temperatura e a umidade são os principais fatores envolvidos na viabilidade embrionária durante a incubação (Boleli, 2003). Umidades relativas menores que $63 \%$ podem reduzir o peso de pintos (Bruzual et. al., 2000) e aumentar o período de incubação (Muraroli \& Mendes, 2003) e a mortalidade embrionária tardia (Decuypere et al., 2003). Incrementos de apenas $0,2^{\circ} \mathrm{C}$ durante a incubação também podem diminuir o período de incubação e afetar a viabilidade embrionária (Christensen et al., 2001).

Diante do exposto, torna-se necessária a avaliação de índices relacionados ao desenvolvimento do embrião e à eclodibilidade de ovos de codornas. O objetivo neste trabalho foi avaliar o efeito do manejo dos ovos durante a estocagem e incubação sobre o desenvolvimento embrionário e a eclodibilidade.

\section{Material e Métodos}

Mil e duzentos ovos férteis foram coletados de um lote de codornas Japonesas com 19 semanas de idade. Os ovos foram coletados às 0,72 ou 144 horas antes do início do processo de incubação, sendo pesados, identificados, acondicionados em embalagens de papelão e armazenados em sala com $26^{\circ} \mathrm{C} \pm 0,5$ de temperatura e $45 \% \pm 2$ de umidade relativa. Os ovos férteis foram propositalmente mantidos em temperatura acima do zero fisiológico, similar à situação normal em ganjas de baixo nível tecnológico.

Para determinação da perda de água durante o estoque, os ovos foram novamente pesados ao início do processo de incubação, sendo embalados individualmente em saquinhos de tule $(10 \times 20 \mathrm{~cm})$ e distribuídos em quatro incubadoras Premium Ecológica com temperatura regulada em 36,5 ou $37,5^{\circ} \mathrm{C}$ e umidade relativa de 55 ou $65 \%$, segundo instruções do fabricante. Os ovos foram mantidos na posição horizontal e foram virados automaticamente a cada duas horas.

Após 276, 324 e 362 horas do início da incubação, dez ovos por tratamento foram coletados, pesados e abertos. $\mathrm{O}$ embrião foi sacrificado por deslocamento cervical e o saco da gema foi extirpado. $\mathrm{O}$ embrião e a casca foram pesados individualmente e as amostras colocadas em estufa a $105^{\circ} \mathrm{C}$ durante 48 horas. Foi determinada a perda de peso, em porcentagem, em diferentes períodos da incubação e a deposição de tecido, um indicativo do desenvolvimento embrionário, foi avaliada a partir dos teores de MS do embrião. Os dados foram expressos em relação ao peso do ovo no momento da coleta.

A partir das 420 horas de incubação, a cada quatro horas, foi determinado o tempo necessário para a eclosão da ave. No momento da eclosão, as codornas e as cascas de seus respectivos ovos foram pesadas individualmente. Dez aves por tratamento foram escolhidas ao acaso, pesadas, insensibilizadas e sacrificadas para determinação do teor de MS.

Ao final de 468 horas, os ovos não eclodidos foram abertos e o período da mortalidade embrionária foi diagnosticado e classificado em precoce (1-4 dias), intermediário (5-15 dias) ou tardio (16-18 dias). O período da mortalidade foi identificado pela análise do estádio de embriogênese da codorna, como o aparecimento do bico e o início da internalização do saco da gema e absorção do líquido amniótico, conforme descrito por Marques (1994). A eclodibilidade (pintos nascidos/ovos férteis incubados) foi determinada desconsiderando os ovos utilizados para determinação do desenvolvimento embrionário.

O delineamento experimental foi inteiramente ao acaso, em esquema fatorial $3 \times 2 \times 2$ (períodos de armazenamento $\mathrm{x}$ temperatura da incubadora $\mathrm{x}$ umidade da incubadora). Em cada tratamento, foram utilizados 100 ovos, cada um representando uma unidade experimental. Os dados quantitativos foram analisados por meio do PROC GLM e comparados pelo teste Tukey; para o fator período de armazenamento, foi feito o estudo da regressão por meio do PROC REG do SAS (1998). Os dados qualitativos foram analisados pelo PROC FREQ e comparados pelo teste Qui Quadrado no software SAS (1998).

\section{Resultados e Discussão}

Produtores de ovos férteis de codornas muitas vezes não contam com equipamentos e tecnologia que possam propiciar o armazenamento com perdas mínimas na qualidade do produto. Neste experimento, o armazenamento à temperatura ambiente ocasionou perda de peso dos ovos $(\mathrm{P}<0,01)$ com o aumento do período de estocagem $\left(\hat{Y}=6,41522^{-15}+0,00830 x ; \hat{r}^{2}=0,78\right)$. A cada dia de armazenagem, o ovo perdeu, em média, 0,2\% do peso. Após 72 e 144 horas de armazenamento, as perdas de peso foram 
de 0,62 e $1,32 \%$, respectivamente, superiores às observadas em ovos férteis de outras espécies armazenados em condições adequadas (Fasenko et al., 2001a, b). Talvez as perdas poderiam ser minimizadas com o estoque dos ovos em temperatura adequada.

Não houve efeitos das interações período de armazenamento $\times$ temperatura $\times$ umidade relativa da incubadora para nenhuma das características avaliadas após 276, 324 e 362 horas de incubação $(P>0,05)$.

Após 276, 324 e 362 horas do início da incubação (12, 14 e 16 dias), a porcentagem de peso dos embriões incubados a $37,5^{\circ} \mathrm{C}$ foi maior que o peso dos embriões incubados a $36,5^{\circ} \mathrm{C}$ (Tabela 1). A deposição de tecido, indicativo do grau de desenvolvimento embrionário, foi maior na temperatura mais elevada. Sabe-se que em aves a temperatura pode interferir na velocidade de desenvolvimento do embrião (Leandro et al., 2000).

A porcentagem de MS do embrião foi influenciada pelo período de armazenamento. $\mathrm{Na}$ amostragem efetuada às 276 horas, maiores porcentagens foram obtidas após 72 ou 144 horas de estocagem. Possivelmente, houve aceleração no desenvolvimento embrionário nos ovos férteis durante a fase de estoque, efetuada acima do zero fisiológico da ave (Fasenko et al., 2001a, b; Christensen et al., 2003), o que refletiu no maior teor de MS na ocasião da análise dos embriões. Na segunda amostragem, efetuada às 324 horas, foi observada maior porcentagem de material somente em ovos submetidos a 144 horas de estoque, indicando que a aceleração no desenvolvimento embrionário observada às 276 horas de incubação só perdurou neste grupo experimental. Ao analisar este mesmo parâmetro após 362 horas de incubação, não foi observado qualquer efeito do período de armazenamento sobre a porcentagem de MS do embrião, indicando que a aceleração que ocorreu anteriormente foi compensada pelos demais grupos experimentais até esta fase da incubação.

A MS do embrião também foi influenciada pela temperatura. De forma similar ao observado anteriormente, maiores quantidades de MS foram obtidas quando os ovos embrionados foram submetidos a maiores temperaturas.

A perda de peso ocorrida às 276,324 e 362 horas de incubação foi influenciada pela umidade da incubadora, sendo observadas maiores perdas nas incubadoras com menor umidade relativa. A perda de peso, ou de água dos ovos, é influenciada pelo ambiente da incubadora onde são feitas trocas gasosas (Decuypere et al., 2003).

A porcentagem de embrião e anexos embrionários não foi influenciada pelo período de armazenamento, pela umidade ou pela temperatura da incubadora em todos os momentos da avaliação, indicando a regularidade no con teúdo total do ovo fértil.

Tabela 1 - Porcentagens de embrião, de embrião + anexos e de MS do embrião em relação ao peso do ovo no dia da coleta e perda de peso do ovo após 276, (276 h), 324 (324 h) e 362 horas (362 h) de incubação

Table 1 - Percentage of embryo, embryo + annex and embryo DM related to egg weight and loss weight of eggs after 276 (276 h), 324 (324 h) and 362 (362 h) hours of incubation

\begin{tabular}{|c|c|c|c|c|c|c|c|c|c|c|c|c|}
\hline \multirow[b]{2}{*}{$\begin{array}{l}\text { Horas de } \\
\text { armazenagem } \\
\text { Hours of storag }\end{array}$} & \multicolumn{3}{|c|}{$\begin{array}{l}\text { Embrião (\%) } \\
\text { Embryos (\%) }\end{array}$} & \multicolumn{3}{|c|}{$\begin{array}{c}\text { Embrião }+ \text { anexos }(\%) \\
\text { Embryos }+ \text { annex }(\%)\end{array}$} & \multicolumn{3}{|c|}{$\begin{array}{l}\text { MS do embrião } \\
\text { Embryos } D M(\%)\end{array}$} & \multicolumn{3}{|c|}{$\begin{array}{c}\text { Perda de peso }(\%) \\
\text { Weight loss }(\%)\end{array}$} \\
\hline & $276 \mathrm{~h}$ & $324 \mathrm{~h}$ & $362 \mathrm{~h}$ & $276 \mathrm{~h}$ & $324 \mathrm{~h}$ & $362 \mathrm{~h}$ & $276 \mathrm{~h}$ & $324 \mathrm{~h}$ & $362 \mathrm{~h}$ & $276 \mathrm{~h}$ & $324 \mathrm{~h}$ & $362 \mathrm{~h}$ \\
\hline 0 & 27,97 & 45,51 & 57,09 & 90,82 & 91,24 & 92,53 & $3,92 y$ & $7,92 b$ & 11,75 & 6,83 & $7,93 n$ & 12,53 \\
\hline 72 & 29,04 & 43,13 & 57,75 & 91,82 & 91,11 & 92,21 & $4,57 x$ & $7,49 b$ & 11,83 & 7,35 & $7,85 \mathrm{n}$ & 10,80 \\
\hline 144 & 31,61 & 44,77 & 58,63 & 91,57 & 91,04 & 92,29 & $4,66 x$ & $8,91 \mathrm{a}$ & 12,24 & 8,40 & $8,31 \mathrm{~m}$ & 10,84 \\
\hline
\end{tabular}

Umidade

Humidity

\begin{tabular}{lrrrrrrrrrrrr}
$55 \%$ & 29,44 & 45,42 & 56,62 & 91,20 & 90,97 & 92,41 & 4,08 & 8,18 & 11,69 & $8,34 \mathrm{x}$ & $9,09 \mathrm{a}$ & $12,49 \mathrm{a}$ \\
$65 \%$ & 29,63 & 45,72 & 58,97 & 91,56 & 91,28 & 92,28 & 4,67 & 8,09 & 12,16 & $6,64 \mathrm{y}$ & $6,95 \mathrm{~b}$ & $10,33 \mathrm{~b}$ \\
\hline $\begin{array}{l}\text { Temperatura } \\
\text { Temperature }\end{array}$ & & & & & & & & & & & & \\
\hline $\begin{array}{l}\text { Tren } \\
36,5^{\circ} \mathrm{C}\end{array}$ & $27,55 \mathrm{y}$ & $41,40 \mathrm{~b}$ & $51,54 \mathrm{n}$ & 91,52 & 90,99 & 92,38 & $3,80 \mathrm{y}$ & $7,19 \mathrm{n}$ & $9,97 \mathrm{n}$ & 7,66 & 7,90 & 10,84 \\
$37,5^{\circ} \mathrm{C}$ & $32,03 \mathrm{x}$ & $50,19 \mathrm{a}$ & $64,49 \mathrm{~m}$ & 91,53 & 91,27 & 92,30 & $5,12 \mathrm{x}$ & $9,18 \mathrm{~m}$ & $14,02 \mathrm{~m}$ & 7,28 & 8,19 & 12,02 \\
$\mathrm{CV}(\%)$ & 18,87 & 8,73 & 8,81 & 1,95 & 0,76 & 1,00 & 16,92 & 11,27 & 13,55 & 27,51 & 25,66 & 26,31 \\
\hline
\end{tabular}

$a, b$ Médias seguidas de letras diferentes na coluna diferem pelo teste Tukey $(P<0,05)$

$x, y$ Médias seguidas de letras diferentes na coluna diferem pelo teste Tukey $(P<0,01)$.

$\mathrm{m}, \mathrm{n}$ Médias seguidas de letras diferentes na coluna diferem pelo teste Tukey $(\mathrm{P}<0,001)$.

$a, b \quad$ Means followed by different letters within a column differ $(P<0.05)$ by Tukey test.

$x, y \quad$ Means followed by different letters within a column differ $(P<0.01)$ by Tukey test.

$m, n \quad$ Means followed by different letters within a column differ $(P<0.001)$ by Tukey test. 
Tabela 2 - Porcentagem de codornas e de MS da codorna no momento da eclosão em relação ao peso do ovo no dia da coleta e ao tempo de incubação necessário para eclosão

Table 2 - Percentage of quails and DM of quail at hatch moment related to weight egg at collection day and incubation time hours necessary to eclosion

\begin{tabular}{lccc}
\hline $\begin{array}{l}\text { Horas de } \\
\text { armazenagem } \\
\begin{array}{l}\text { Hours of } \\
\text { storage }\end{array}\end{array}$ & $\begin{array}{c}\text { Codorna (\%) } \\
\text { Quail }(\%)\end{array}$ & $\begin{array}{c}\text { MS da codorna (\%) } \\
\text { Quail DM (\%) }\end{array}$ & $\begin{array}{c}\text { Eclosão (h) } \\
\text { Hatch }(h)\end{array}$ \\
\hline 0 & & & \\
72 & 57,09 & 11,75 & $433,8 \mathrm{n}$ \\
144 & 57,75 & 11,83 & $425,9 \mathrm{~m}$ \\
Umidade & 58,63 & 12,24 & $424,1 \mathrm{~m}$ \\
Humidity & & & \\
\hline $55 \%$ & & & $429,2 \mathrm{y}$ \\
$65 \%$ & 56,62 & 11,69 & $426,8 \mathrm{x}$ \\
\hline
\end{tabular}

Temperatura

Temperature

\begin{tabular}{lrrr}
\hline $36,5^{\circ} \mathrm{C}$ & $51,54 \mathrm{~b}$ & $9,97 \mathrm{~b}$ & $442,5 \mathrm{n}$ \\
$37,5^{\circ} \mathrm{C}$ & $64,49 \mathrm{a}$ & $14,02 \mathrm{a}$ & $413,6 \mathrm{~m}$ \\
$\mathrm{CV}(\%)$ & 8,81 & 13,55 & 3,43 \\
\hline
\end{tabular}

$\mathrm{a}, \mathrm{b}$ Médias seguidas de letras diferentes na coluna diferem pelo teste Tukey $(P<0,05)$.

$x, y$ Médias seguidas de letras diferentes na coluna diferem pelo teste Tukey $(P<0,01)$

m, n Médias seguidas de letras diferentes na coluna diferem pelo teste Tukey $(\mathrm{P}<0,001)$.

a,b Means followed by different letters within a column differ $(P<0.05)$ by Tukey test. $x, y \quad$ Means followed by different letters within a column differ $(P<0.01)$ by Tukey test. $m, n \quad$ Means followed by different letters within a column differ $(P<0.001)$ by Tukey test.

Não houve efeito da interação período de armazenamento $\times$ temperatura $\times$ umidade relativa da incubadora para as características avaliadas no momento da eclosão dos ovos ( $\mathrm{P}>0,05)$.

No momento da eclosão, a codorna apresentou maior porcentagem de peso e maior porcentagem de MS em função da temperatura da incubadora (Tabela 2). Maiores animais foram obtidos em maior temperatura.

Ovos armazenados durante 72 ou 144 horas eclodiram mais rápido que os não estocados. Embora o desenvolvimento das aves avaliado pela quantidade de MS não tenha sido influenciado pelo período de armazenamento $(\mathrm{P}>0,05)$, os animais realizaram a ruptura da casca com, em média, 8,9 horas de antecedência.

A umidade da incubadora também influenciou a velocidade de eclosão dos ovos. Ovos incubados a $65 \%$ de umidade relativa eclodiram mais rápido, em oposição ao observado por Bruzual et al. (2000), em pintos de corte. Entretanto, Marques (1994) afirmou que ovos com muita liberação de umidade, em virtude da características da casca, podem ser submetidos a altas umidades relativas, acima de $65 \%$. Talvez as características físicas da casca dos ovos das codornas tenham contribuído para esse resultado,
Tabela 3 - Freqüência (\%) do período de mortalidade de ovos férteis de codornas armazenados por diferentes períodos

Table 3 - Frequency (\%) of mortality period of quail fertile eggs stored by different periods

\begin{tabular}{|c|c|c|c|c|}
\hline & \multicolumn{4}{|c|}{$\begin{array}{c}\text { Horas de armazenagem } \\
\text { Hours of storage }\end{array}$} \\
\hline & 0 & 72 & 144 & Total \\
\hline Precoce & 6,26 & 7,74 & 20,88 & 34,87 \\
\hline $\begin{array}{l}\text { Earlier } \\
\text { Intermediária } \\
\text { Intermediary }\end{array}$ & 2,46 & 0,77 & 3,93 & 7,16 \\
\hline Tardia & 4,14 & 5,36 & 9,20 & 18,70 \\
\hline $\begin{array}{l}\text { Late } \\
\text { Após bicagem }\end{array}$ & 10,55 & 13,97 & 14,75 & 39,26 \\
\hline $\begin{array}{l}\text { After breaking } \\
\text { Total }\end{array}$ & 23,41 & 27,83 & 48,76 & 100,00 \\
\hline
\end{tabular}

visto que a casca do ovo desta espécie é menos espessa e pode apresentar perdas maiores que nas matrizes de corte.

De forma similar, a maior temperatura antecipou a eclosão dos ovos. Em pintos de corte, temperaturas abaixo do limiar considerado adequado $\left(37,5^{\circ} \mathrm{C}\right)$ podem aumentar o período de incubação (Romanoff, 1936). Leandro et al. (2000) observaram que o processo de incubação pode atrasar até 10,2 horas quando a ave é submetida a temperaturas abaixo do desejado.

A freqüência da mortalidade embrionária não foi influenciada $(P>0,05)$ pela interação período de armazenamento $\times$ temperatura $\times$ umidade relativa da incubadora.

Ovos estocados durante 144 horas apresentaram maior mortalidade embrionária que os estocados por até 72 horas $(\mathrm{P}<0,01)$. Dos ovos com embriões mortos, 48,76; 27,83 e $23,41 \%$ foram observados nos ovos armazenados durante 144,72 e 0 hora, respectivamente. $\mathrm{O}$ tempo de armazenagem também influenciou o período de ocorrência da mortalidade $(\mathrm{P}<0,03$; Tabela 3). Após 144 horas de armazenagem, a mortalidade precoce do embrião foi maior que nos demais grupos experimentais.

A estocagem de ovos férteis interfere na mortalidade embrionária (Brake et al., 1997), que, na fase precoce, após períodos de armazenamento, é atribuída a alterações no blastoderme, que ocasionam má formação (Boleli, 2003), deterioração na qualidade do albúmem (Lapão et al., 1999) e, conseqüentemente, a morte do embrião.

A umidade da incubadora não influenciou significativamente a quantidade total de embriões mortos $(\mathrm{P}>0,05)$, mas afetou a fase de ocorrência (Tabela 4). A mortalidade após a bicagem da casca foi maior no grupo incubado a $65 \%$ de umidade relativa $(\mathrm{P}<0,05)$. Tem-se observado que a alta umidade relativa pode resultar em maior número de ovos bicados (Wilson, 2004). Entretanto, neste experimento, a 
Tabela 4 - Freqüência (\%) do período de mortalidade em ovos férteis de codornas incubados sob diferentes umidades relativas

Table 4 - $\quad$ Frequency (\%) of mortality period of quail fertile eggs incubated at different relative humidity

\begin{tabular}{|c|c|c|c|}
\hline & \multicolumn{3}{|c|}{$\begin{array}{l}\text { Umidade } \\
\text { Humidity }\end{array}$} \\
\hline & $55 \%$ & $65 \%$ & Total \\
\hline Precoce & 18,56 & 16,31 & 34,87 \\
\hline $\begin{array}{l}\text { Earlier } \\
\text { Intermediária } \\
\text { Intermediary }\end{array}$ & 1,60 & 5,57 & 7,16 \\
\hline $\begin{array}{l}\text { Tardia } \\
\text { Late }\end{array}$ & 10,70 & 8,00 & 18,70 \\
\hline Após bicagem & 16,39 & 22,87 & 39,26 \\
\hline $\begin{array}{l}\text { After breaking } \\
\text { Total }\end{array}$ & 47,26 & 52,74 & 100,00 \\
\hline
\end{tabular}

umidade não afetou a eclodibilidade total dos ovos férteis, corroborando a teoria de Murakami \& Ariki (1998) de que $70 \%$ de umidade relativa durante a fase de eclosão das codornas promove bons resultados.

As diferentes temperaturas avaliadas não influenciaram a mortalidade embrionária e sua fase de ocorrência (P>0,05), indicando grande tolerância dos embriões de codornas à amplitude térmica testada.

$\mathrm{O}$ armazenamento à temperatura ambiente influenciou a eclodibilidade dos ovos. Às 0,72 e 144 horas, a porcentagem de eclosão foi de $83,54 \% \pm 1,51,80,44 \% \pm 4,54$ e $65,73 \%$ $\pm 8,70$, respectivamente. A eclosão dos ovos férteis foi significativamente menor após 144 horas de armazenagem ( $\mathrm{P}>0,001)$, possivelmente como resultado de alterações químicas e fisiológicas no conteúdo de ovo e de embrião.

A eclodibilidade nos ovos incubados sob umidade relativa de 55 e $65 \%$ foi de $77,85 \% \pm 7,38$ e de $75,28 \% \pm 12,07$, respectivamente. Para as temperaturas de 36,5 e $37,5^{\circ} \mathrm{C}$, a eclodibilidade foi de 76,57\% 7,60 e 76,55\% $\pm 12,09$ e diferiu significativamente entre os tratamentos adotados $(\mathrm{P}>0,05)$.

\section{Conclusões}

Ovos férteis de codornas podem ser armazenados à temperatura ambiente $\left(26,5^{\circ} \mathrm{C}\right)$ por até 72 horas e incubados a $37,5^{\circ} \mathrm{C}$ e a 55 ou $65 \%$ de umidade relativa.

\section{Agradecimento}

À Dra. Alice Eiko Murakami e ao Dr. Luís Daniel Giusti Bruno, pela doação das matrizes para a realização do experimento, e ao CNPq, pela concessão da bolsa de pesquisa à primeira autora.

\section{Literatura Citada}

APPLEGATE, T.J.; DIBNER, J.J.; KITCHELL, M.L. Effect of turkey (Meleagridis gallopavo) breeder hen age and egg size on poult development. 2. Intestinal villus growth, enterocyte migration and proliferation of the turkey poult. Comparative Biochemistry and Physiology Part B: Biochemistry and Molecular Biology, v.124, n.4, p.381-389, 1999.

BOLELI, I.C. Fatores que afetam a eclodibilidade e qualidade dos pintos. In: MACARI, M.; GONZALES, E. (Eds.) Manejo da incubação. 2.ed. Campinas: Fundação APINCO de Ciência e Tecnologia Avícolas, 2003. p.394-434.

BRAKE, J.; WALSH, T.J.; BENTON, C.E. et al. Egg handling and storage. Poultry Science, v.76, n.1, p.144-151, 1997.

BRUZUAL, J.J.; PEAK, S.D.; BRAKE, J. et al. Effects of relative humidity during incubation on hatchability and body weight of broiler chicks from young breeder flocks. Poultry Science, v.79, n.6, p.827-830, 2000 .

CHENG, Y.S.; ROUVIER, R.; POIVEY, J.P. Selection responses in duration of fertility and its consequences on hatchability in the intergeneric crossbreeding of ducks. British Poultry Science, v.46, n.5, p.565-571, 2005.

CHRISTENSEN, V.L.; GRIMES, J.L.; WINELAND, M.J. et al. Accelerating embryonic growth during incubation following prolonged egg storage. 1. Embryonic livability. Poultry Science, v.82, n.12, p.1863-1868, 2003.

CHRISTENSEN, V.L.; WINELAND, M.J.; FASENKO, G.M. et al. Egg storage effects on plasma glucose and supply and demand tissue glycogen concentrations of broiler embryos. Poultry Science, v.80, n.12, p.1729-1735, 2001.

DECUYPERE, K.; MALHEIROS, R.D.; MORAES, V.M.B. et al. Fisiologia do embrião. In: MACARI, M.; GONZALES, E. (Eds.) Manejo da incubação. 2.ed. Campinas: Fundação APINCO de Ciência e Tecnologia Avícolas, 2003. p.65-94.

DECUYPERE, K.; MICHELS, H. Incubation temperature as a management tool: a review. World's Poultry Science Journal, v.48, n.1, p.27-38, 1992.

FASENKO, G.M. Factors influencing embryos and poult viability and growth in stored turkey eggs. Reileigh: North Caroline State University, 1996. 114p. Thesis (Ph.D. in Agricultural, Food and Nutritional Science) - North Caroline State University, 1996.

FASENKO, G.M.; ROBINSON, F.E.; WHELAN, A.I. et al. Examining the effects of prestorage incubation of turkey breeder eggs on embryonic development and hatchability of eggs stored for four or fourteen days. Poultry Science, v.80, n.1, p.132-138, $2001 \mathrm{a}$.

FASENKO, G.M.; ROBINSON, F.E.; WHELAN, A.I. et al. Prestorage incubation of long-term stored broiler breeder eggs: 1. Effects on hatchability. Poultry Science, v.80, n.10, p.1406-1411, $2001 b$

LAPÃO, C.; GAMA, L.T.; SOARES, M.C. Effects of broiler breeder age and length of egg storage on albumen characteristics and hatchability. Poultry Science, v.78, n.5, p.640-645, 1999.

LEANDRO, N.S.M.; GONZALES, E.; VAROLI JR., J.C.V. et al. Hatchability and chick quality of broiler breeder eggs submitted to stress due to temeperature. Revista Brasileira de Ciência Avícola, v.2, n.1, p.39-44, 2000.

MARQUES, D. Fundamentos básicos de incubação industrial. 2.ed. São Paulo: CASP, 1994. 22p.

MEIJERHOF, R.; NOORDHUIZEN, J.P.; LEENSTRA, F.R. Influence of pre-incubation treatment on hatching results of broiler breeder eggs produced at 37 and 59 weeks of age. British Poultry Science, v.35, n.2, p.249-257, 1994.

MURAKAMI, A.; ARIKI, J. Produção de codornas japonesas. Jaboticabal: FUNEP, 1998. 79p.

MURAROLI, A.; MENDES, A.A. Manejo da incubação, transferência e nascimento do pinto. In: MACARI, M.; 
GONZALES, E. (Eds.) Manejo da incubação. 2.ed. Campinas: Fundação APINCO de Ciência e Tecnologia Avícolas, 2003. p.180-198.

REIS, L.H.; GAMA, L.T.; SOARES, M.C. Effects of short storage conditions and broiler breeder age on hatchability, hatching time, and chick weights. Poultry Science, v.76, n.11, p.14591466, 1997.

ROMANOFF, A.L. Effects of different temperature in the incubator on the prenatal and postnatal development of the chick. Poultry Science, v.15, n.1, p.311-315, 1936.

SAHAN, U.; ALTAN, O.; IPEK, A. et al. Effects of some egg characteristics on the mass loss and hatchability of ostrich (Struthio camelus) eggs. British Poultry Science, v.44, n.3, p.380-385, 2003.
STATISTICAL ANALYSES SYSTEM - SAS. User's guide: statistics. Version 8, v.2, Cary: 1998. 634p.

Van BRECHT, A.; AERTS, J.M.; DEGRAEVE, P. et al. Quantification and control of the spatiotemporal gradients of air speed and air temperature in an incubator. Poultry Science, v.82, n.11, p.1677-1687, 2003.

WILSON, H.R. Hatchability problems analysis. University of Florida, 2004. p.1-13 (Institute of Food and Agricultural Sciences Extension, CIR1112).

Recebido: 04/07/05 Aprovado: 26/06/06 